\title{
Como dar significado social e científico ao cotidiano do aluno
}

\author{
MARIA APARECIDA PEREZ*
}

\section{Quando exerci o cargo de Chefe de Gabinete e, depois,} de Secretária de Educação da cidade de São Paulo, de fevereiro de 2002 a dezembro de 2004, no Governo Marta Suplicy, pude observar e acompanhar o desenvolvimento de vários projetos junto a escolas localizadas em diferentes regiões urbanas, em especial, na periferia. Considerávamos esses projetos especiais porque não se relacionavam diretamente com o currículo escolar.

Na própria estrutura organizacional da Secretaria, esses projetos, quando propostos para as unidades escolares, eram acompanhados por uma equipe pedagógica específica, diferente das que eram responsáveis pedagogicamente pelas áreas de educação infantil e pelo ensino fundamental. Vejamos alguns deles:

Educom Rádio: nasceu em 2001, de um contrato entre a Secretaria de Educação da Prefeitura de São Paulo e o Núcleo de Comunicação e Educação da Escola de Comunicações e Artes da Universidade de São Paulo - NCE ECA-USP, com o objetivo de construir, nas escolas públicas, um ambiente favorável às manifestações da cultura de paz e à colaboração mútua entre os membros da comunidade educativa, combatendo as manifestações da violência, tanto física quanto simbólica. Para tanto, o NCE trabalha com a linguagem radiofônica, envolvendo professores, alunos e membros da comunidade educativa. 0 projeto destina-se a capacitar alunos e professores do ensino fundamental para o uso de práticas de educomunicação por meio do uso do rádio.

A cidade que a gente quer: esse projeto foi desenvolvido em parceria com o MIT. Permite aos participantes projetar e construir modelos e criar outras formas de expres-

* Maria Aparecida Perez é ex-secretária de educação da cidade de São Paulo e doutoranda do International Education Doctorate Program - INEDD, do Departamento de Educação da Universidade de Siegen. são voltadas para a melhoria da qualidade de vida na cidade de São Paulo, expressando suas idéias através das novas e tradicionais tecnologias e materiais diversos. Envolve diversas áreas do conhecimento de forma significativa e contextualizada; desenvolve habilidades de trabalhos em grupos, pesquisa e questionamento crítico da vida, da cultura e do funcionamento da cidade em que se vive. 0 projeto também possibilita habilidades e vivências úteis ao desenvolvimento pessoal dos participantes, além de conteúdos como informática, edição de vídeo, animação, robótica e componentes eletrônicos.

RPG - Rolling Player Game: jogo de encenação ou de dramatização que pode ser praticado de forma vivenciada, com pessoas reais representando personagens, ou de forma eletrônica, por meio do computador. 0 RPG tem se tornado um poderoso recurso educacional, pois todo e qualquer tema pode ser adaptado e desenvolvido, tais como: meio ambiente, diversidade cultural, saúde, consumo, relações sociais, e assim por diante. 0 desenvolvimento da história e seus personagens, construção de cenários e fantasias exige pesquisa sobre os temas, escrita, cálculo etc. Possivelmente, a maior contribuição do RPG seja a de simular desafios constantes para os participantes, permitindo que cada um assuma características do personagem e descubra, brincando, novas formas de agir na vida real.

Mão na Massa: ensino de Ciências por meio de um tema gerador - um projeto internacional, fruto da cooperação entre as Academias de Ciências francesa e brasileira, que visa à melhoria da educação científica, especialmente nas séries iniciais do ensino fundamental. As práticas de formação do projeto permitem aos educadores visualizar a construção dos mapas conceituais e a rede de conhecimento, bem como a construção dos conteúdos significativos a partir da realida- 
de da criança, da escola e da comunidade. A utilização dos kits da Experimentoteca como recurso e não como fim didático-pedagógico em sala de aula permite, aos educadores, destacar a contextualização e a problematização investigativa.

Apita Já: projeto de Educação para o Trânsito, desenvolvida por intermédio de jogos grupais de raciocínio. Os jovens vão para as ruas, no entorno da escola, para conhecer a realidade do trânsito e de mobilidade enfrentada pela comunidade, eles colherão informações através de "estudos do meio" e criarão, num exercício democrático, projetos de intervenção. Da comunidade, espera-se o seu engajamento na causa para que os jovens possam concretizar suas ações. A idéia é que seja criado um espaço para o diálogo e que, por meios deste exercício democrático, estas ações possam realmente responder aos anseios destas comunidades por uma melhor qualidade de vida. As propostas complexas para sua realização, por exemplo, passarelas para pedestres, introdução de linhas de ônibus, asfaltamento etc. foram encaminhadas às autoridades competentes.

Primavera da Paz: Festival de Bandas e Fanfarras, instituído por lei, para acontecer na primavera, aliado a um tema escolhido pelas escolas, como Direitos Humanos, Dia do Amigo etc. Uma comissão intersecretarial, composta pelas várias Secretarias Municipais sob a coordenação da Secretaria Municipal de Educação, é encarregada da sua organização. Os alunos, junto com o professor de música e outros profissionais da escola, pensam na música, no uniforme, na coreografia que nem sempre respeita o formato da banda marcial. Elaboram o cronograma e o formato do Festival.

450 anos de São Paulo: visita a exposições; excursões aos locais vistos em fotos antigas; pesquisa, produção e expressão de idéias sobre São Paulo, por meio de desenho, pintura, fotografia ou escrita. Este trabaIho resultou numa publicação de 35 livros, 31 representando as escolas de cada uma das subprefeituras; um livro produzido pelos índios Guaranis nos CECl's; um livro pelos alunos do MOVA; um pelo CEU Frances e um pelo CEU Italiano, estes dois últimos, fruto de convênios com os consulados onde era ofertado o ensino bilíngüe.

Banco na Escola: uma ação voltada para a formação de alunos, pais, professores e comunidade escolar, para a compreensão do Orçamento Municipal, principalmen- te no que diz respeito à aplicação dos recursos destinados à Educação. As metodologias pedagógicas, processos comunicativos contextualizados e tecnologias digitais em redes locais ou globais, quando bem utilizadas, podem propiciar a aprendizagem (individual ou coletiva) assistida por computador, conectado ou não em redes telemáticas. Desenvolver as chamadas competências de letramento informacional (verbal e numérico) implica fazer uso da leitura das normas fiscais e dos relatórios orçamentários, compreendê-los e debatê-los coletivamente, para colocá-los em ação, na prática.

\section{Desenvolver o educando e o conhecimento}

\section{Todas as atividades desenvolvidas por esses projetos}

atraíam os educandos e, na maioria das vezes, aqueles considerados os "mais terríveis e indisciplinados" eram os que participavam mais ativamente delas, sentiam orgulho em apresentar seus trabalhos publicamente e mostravam mudança de comportamento ao perceber que as várias formas de aprender extrapolavam a sala de aula, onde ficavam sentados, ouvindo e copiando.

Com o tempo, fomos notando quanto esses projetos dialogavam com o conteúdo escolar e quanto conquistavam as crianças e, principalmente, os adolescentes. Essa constatação implicava várias perguntas:

- O que esses projetos proporcionavam aos educandos?

- O que e como esses alunos aprendiam?

- Por que essas atividades atraíam os mais rebeldes?

Na prática, na sala de aula, o professor tem diversas formas de apresentar o conhecimento para o aluno e gostaríamos de nos deter em duas delas que, sob nosso olhar, são as mais deficitárias.

Tomando como base as reflexões de Bernd Fichtner, podemos dizer que, numa primeira forma, o professor apresenta o conhecimento acabado, definido; assim, o conteúdo do ensino é entendido e percebido só como um resultado já pronto. Ensinar, desse modo, significa uma simples transmissão literal de objetos e palavras do livro didático para os educandos. 0 ensino, neste caso, tem por objetivo a "fundamentação" de conhecimentos já prontos. E as conseqüências são bem conhecidas por nós: o educando é como um vasilhame onde "depositamos" conhecimento, como guardamos objetos.

Numa segunda forma, o ensino é orientado apenas para o processo comunicativo, interativo, portanto, a co- 
municação é mais significativa do que o conteúdo. Nessa concepção, o contexto ensino-aprendizagem é, acima de tudo, uma inter-relação de interpretações, expectativas e compreensões, e a sala de aula passa a ser um lugar de expressões, sem nenhuma base para a construção real de conhecimento. Fala-se sobre algo, mas não se constrói o conteúdo mediante a própria atividade.

Em ambos os casos, objeto e atividade de aprendizagem estão separados por não considerarem os sujeitos sociais envolvidos na ação. São propostas que se encaminham para o inverso do processo de aprendizagem desejado, ou seja, um processo de atividade e, ao mesmo tempo, de desenvolvimento tanto do sujeito (educando) quanto do objeto (conhecimento).

As atividades de aprendizagem de "fundamentação" e "desenvolvimento" necessitam ser dialógicas para que os educandos sejam sujeitos da sua própria aprendizagem, de forma que as práticas pedagógicas ganhem sentido à medida que o conteúdo das matérias se relacione com o cotidiano do educando.

Olhar de novo para o que considerávamos projetos especiais exige uma série de reflexões:

- Por que não trocar a sala de aula por outros ambientes, até externos à escola, à sua volta?

- Por que não incentivar a comunidade do entorno da escola a participar do seu projeto político-pedagógico?

- Por que não usar o lúdico nas matérias, como em Matemática, Ciências etc.?

- E a arte e suas várias linguagens, onde elas aparecem?

- Por que não possibilitar ao educando organizar suas ações em função de um tema proposto e de um resultado esperado?

- Por que não conversar sobre os interesses dos alunos e, dialogicamente, tratá-los nas aulas, relacionandoos ao currículo?

Depois da minha experiência na Secretaria e observando outras experiências nacionais e internacionais, acredito que, se não vivenciarmos, no âmbito escolar, as contradições - sociais, culturais, econômicas e ambientais - não teremos como responder às perguntas iniciais, tornando a escola atraente ou uma "belezura", como dizia Paulo Freire.

O educando, a partir de um tema proposto, pode organizar a pesquisa, pensar no formato do projeto e como apresentá-lo, escrever sobre ele, organizar seu tempo, num pacto com os outros educandos que comporão seu grupo e o professor responsável.
Assim, poderá realizar-se uma conexão entre generalização e troca, entre pensamento e comunicação, entre curiosidade e objetivo, permitindo que o aluno perceba a sua capacidade de compreender as representações do conhecimento na Matemática, Química, Biologia, Física, Português, Artes, Geografia, História etc.

0 novo não tem formas velhas para se apresentar. 0 novo tem a ver com a possibilidade de o estudante refletir, numa postura pró-ativa, sobre as informações recebidas, e construir novas relações entre o saber estabelecido, o próprio saber e o processo de descoberta.

Respeitar o educando como sujeito social exige uma nova organização didática e novas posturas dos professores e especialistas da educação. "A minha sala de aula, o meu aluno, a minha matéria” são expressões que precisam desaparecer.

\section{Prática coletiva}

\section{Todos os projetos citados, embora se apresentem com}

nome e objetos de estudo diferentes, têm em comum o uso de Roteiro de Pesquisa e dos Planos de Estudo, sem desprezar as tradicionais tecnologias, como a lousa, o giz ou o livro, nem as novas, como os computadores, na busca de informação. E o que são estes Roteiros e Planos? Nada que seja desconhecido por nós, educadores, mas dificilmente praticado coletivamente.

Os Roteiros, como vêm sendo aplicados na experiência da EMEF Amorim Lima, em São Paulo, tratam de temas e não de disciplinas. Os temas relacionam as matérias e os conteúdos curriculares sem separá-los - por exemplo, o aprendizado da escrita da palavra água é trabalhado em conjunto com o seu significado social e científico, relacionando-a ao cotidiano do aluno.

Os Planos de Estudo e Roteiros são planejados com os professores e pactuados com o aluno e as equipes que se formam entre eles desde o início do ano. 0 estudo é coletivo, os alunos devem organizar seu tempo e a hierarquia dos temas de acordo com seus interesses. Todos sabem que, durante o ano letivo, terão que dar conta de todos os temas constantes dos Roteiros:

\footnotetext{
O trabalho de pesquisa é norteado por Roteiros Temáticos de Pesquisa, concebidos segundo a teoria dialógica de Bakhtin, e apoiado nos livros didáticos e paradidáticos. Apesar de usar tais livros de forma particular e não seqüencial, privilegiando uma transversalidade temática, e apesar de não se restringir a eles, o
} 
Respeitar o educando

como sujeito social

exige uma nova

organização didática

e novas posturas

dos professores $e$

especialistas da

educação. A minha

sala de aula, o meu

aluno, a minha matéria"

são expressões que

precisam desaparecer.

Projeto reconhece o Plano Nacional do Livro Didático - PNLD como outra importante base prática e conceitual, além da sustentação em uma Política Pública Federal.

Além do acompanhamento grupal e individual em sala, os alunos são acompanhados mais de perto por um tutor que, ao se ater a um grupo menor de alunos, poderá orientá-los com olhar mais atento e agudo, indicando e corrigindo rumos.

Sendo a busca da autonomia um valor matricial do Projeto, e somente podendo ela fundar-se cada vez mais numa auto-avaliação, cabe, preferencialmente, ao espaço da tutoria implantare fomentar a auto-avaliação, numa gradual tomada de consciência, por parte dos alunos e educadores, de suas capacidades e de suas dificuldades.

EMEF Amorim Lima - Projeto Pedagógico

A experiência precisa se tornar possível, de forma que o novo e o desconhecido tenham lugar no processo de aprendizagem. Novas propostas, como os roteiros de pesquisas, precisam ser estruturadas para conter o fundamento de sua própria explicação e do seu próprio desenvolvimento, isto é, para que não sejam inteiramente reduzíveis àquilo que já é conhecido e familiar.

Portanto, o desafio do professor seria o de mostrar que o conhecimento, inclusive o já existente, é um processo de descoberta, fruto da curiosidade, abrindo assim, para os alunos, a consciência da capacidade humana para a construção de novos conhecimentos.

A relação entre o conteúdo e a aprendizagem na sala de aula precisa ser construída para despertar o novo sem se fechar na eterna repetição do já sabido.
Referências

ABRAMO, H. W.; MARTONI, B. (Org.). Retratos da juventude brasileira - análise de uma pesquisa nacional. São Paulo: Instituto da Cidadania e Fundação Perseu Abramo, 2005.

CENPEC; ITAÚ SOCIAL; UNICEF. Muitos lugares para aprender. São Paulo, 2003. (Col. Educação \& Participação).

FICHTNER, Bernd. A escola histórico-cultural e a Teoria da Atividade: sua importância na pedagogia moderna. Cadernos de Pesquisa, Universidade Federal de Santa Maria/Centro de Educação, p. 4-21, 1995.

. Ensinar e aprender - um diálogo com o futuro: a abordagem de Vygotky. In: SILVA, Luis Heron; AZEVEDO, José Clóvis; SANTOS, Edmilson dos Santos (Org.). Identidade social e a construção do conhecimento. Porto Alegre: Prefeitura Municipal de Porto Alegre, 1997. p. 146-177.

. A abordagem histórico-cultural na educação. Paixão de Aprender, Porto Alegre, Secretaria Municipal de Educação e Prefeitura Municipal de Porto Alegre, n. 10, p. 44-56, mar. 1997.

FREIRE, P. Educação como prática de liberdade. Rio de Janeiro: Paz e Terra, 1999.

. Pedagogia do oprimido. Rio de Janeiro: Paz e Terra, 2001.

GENTILI, P.; MCCOWAN, T. (Org.). Reinventar a escola pública. Rio de Janeiro: Editora Vozes, 2003.

PEREZ, M. A. A Educação e a construção da política de combate à exclusão. II Conferência Internacional da Rede 10 - Luta contra a pobreza urbana, fev. 2004.

PEREZ, M. A. Rumbo a uma ciudad educadora: la educacion y la construccion de uma política de combate contra la exclusion. IDEP - Revista Educación y Ciudad, n. 7, p. 107 a 126, out. 2005.

SME-SP. Revistas das Coordenadorias de Educação - Projeto Político-Pedagógico.

SME-SP. Revistas EducAção, n. 1 a 4.

VYGOTSKY, L. S. A formação social da mente. São Paulo: Martins Fontes, 1984. LURIA, A. R., LEONTIEV, A. N. Linguagem, desenvolvimento e aprendizagem. São Paulo: Ícone/Edusp, 1988.

\section{Sites}

〈http://www.amorimlima.com.br/novo/index.asp〉 〈www.eb1-ponte-n1.rcts.pt〉 


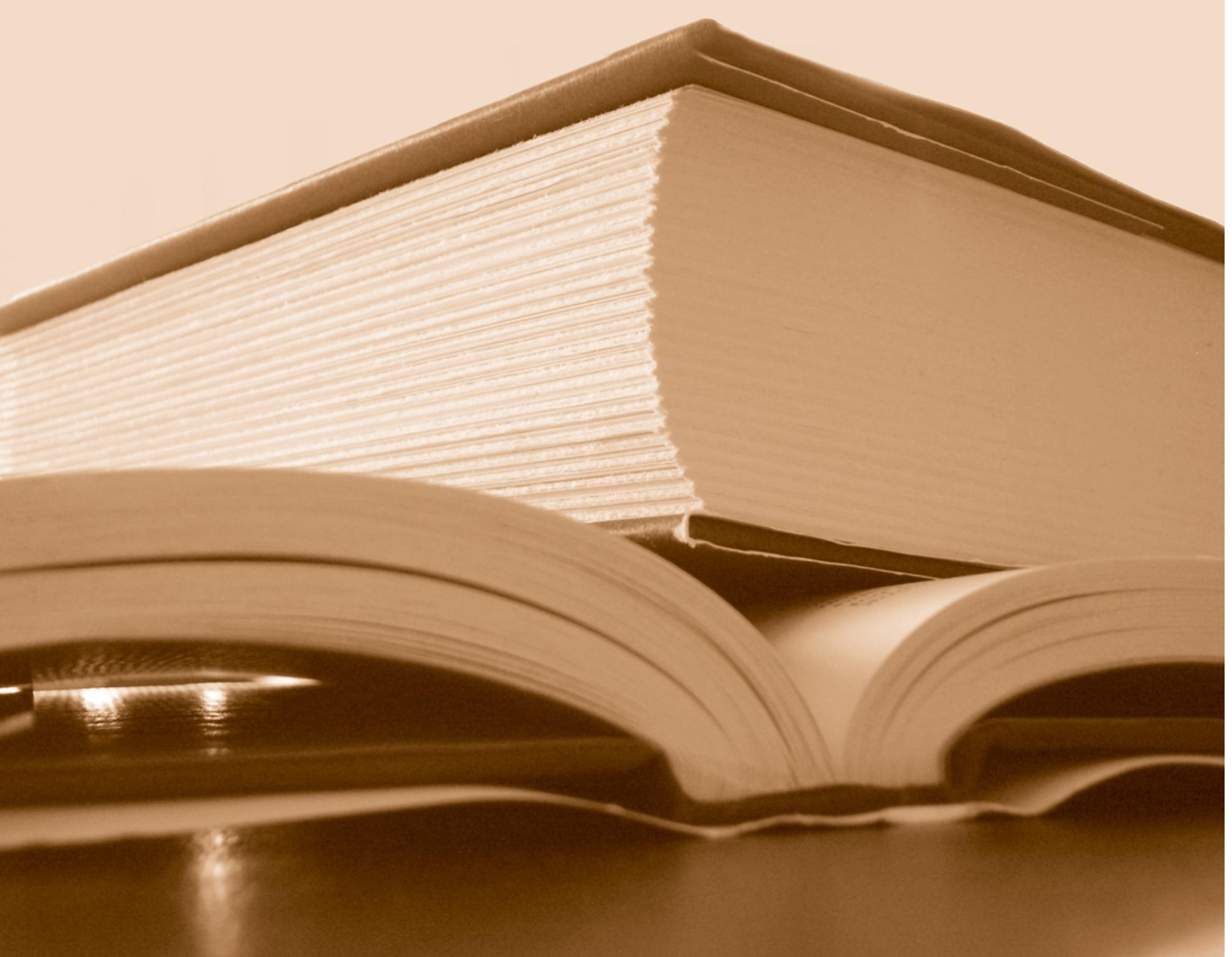

